AC 2011-867: PROBLEM BASED LEARNING USING HARP INSTRUCTION

Dr. Stephen Snyder, Taylor University

Professor of Psychology Fellow of the Center of Teaching Excellence Director of the Social Science Research Training Program

Rachel Tomasik

Bethany Smith, Taylor University 


\section{Problem-Based Learning Using HARP Instruction}

\section{Abstract}

A project-based model of teaching was used for the New Height's High Altitude Research Platform (HARP) program in 29 science classrooms that contained 849 students. This educational model assumes that learning and doing are inseparable to the learning process. Direct instruction and project-based work were used to enhance the HARP experiments in the science curriculum. A pretest and a posttest were given to students in classes that used high altitude ballooning as an event without implementing problem-based learning (event group). An integrated problem-based curricular experience was done once (novice group), two or three times (experienced group) or more than three times (expert group) by professors using a reliable $(\alpha=$ $.955)$ and valid (known group difference method) instrument to assess key educational variables.

When comparing the event group (control group), novice group, experienced group, and the expert group, there was a statistically significant difference between them in intrinsic motivation $(\mathrm{p}<.05)$, valuing science $(\mathrm{p}<.001)$, application knowledge $(\mathrm{p}<.001)$, metacognitive processes $(p<.001)$, cognitive skills $(p<.001)$, and content knowledge $(p<.001)$.

Professors that integrated HARP into their classes with instructive feedback two or three times (experienced group) were able to achieve growth in their students in key educational variables equivalent to that observed in the expert group classrooms. The experienced group showed statistical significant changes from the students pretest to posttest in intrinsic motivation $(\mathrm{p}<.001)$, valuing science $(\mathrm{p}<.01)$, application knowledge $(\mathrm{p}<.001)$, metacognitive processes $(p<.001)$, cognitive skills $(p<.001)$, and content knowledge $(p<.001)$. The experienced group's educational gains were found to be practically significant in the key educational objectives of metacognitive processes $\left(\eta^{2}=.221\right)$ and content knowledge $\left(\eta^{2}=.387\right)$.

The expert groups continued to be evaluated and received constructive feedback on how to improve their problem-based teaching approach in implementing the HARP program into their curriculum. After four semesters of implementation and feedback on how to improve, all major educational variables measured were both statistically and practically significant when comparing their students' improvements from pretests to posttests. The statistical and practical significance of the students' improvement during the semester occurred in intrinsic motivation $\left(\mathrm{p}<.001 ; \eta^{2}=.418\right)$, valuing science $\left(\mathrm{p}<.001 ; \eta^{2}=.559\right)$, application knowledge $\left(\mathrm{p}<.001 ; \eta^{2}=\right.$ $.602)$, metacognitive knowledge $\left(p<.001 ; \eta^{2}=.492\right)$, cognitive skills $\left(p<.001 ; \eta^{2}=.738\right)$, and content knowledge $\left(\mathrm{p}<.001 ; \eta^{2}=.738\right)$.

Introduction

Introduction of Problem

The problem that was addressed was whether a problem-based model, improved by current educational literature on problem-based learning with continual feedback on key educational variables, improves student learning in science classes. 
Problem-Based Teaching Model

The HARP program was structured around the macrostructure of problem-based learning rather than traditional information-based learning experience. Meta-analyses on problem-based instruction show improvements superior to traditional information driven by information in the area of skills and application knowledge as well as intrinsic motivation, and metacognitive knowledge. ${ }^{1-2}$ Because the purpose of the HARP program was to develop these key educational objectives, the problem-based structure was a natural fit.

Segers (2003) in his meta-analysis of 43 articles on problem-based learning structure vs. an information lecture style structure found that knowledge is deepened significantly more through a problem-based approach. ${ }^{1}$ This was also consistent with another meta-analysis that indicated that problem-based instruction resulted in more than traditional information-based knowledge when knowledge was measured by levels of understanding principles that link concepts. $^{2,3}$ Because this was the goal of the HARP program, this made this approach a better one to use. Nandi (2000) and Segers (2003) also found that conceptual knowledge needed to be given by the instructor if the aspects of the problem solving needed to use these concepts or methods along with the instruction. ${ }^{4,1}$ To accommodate this need, direct instruction and group work were used to enhance weekly group problem solving projects being conducted.

\section{Relevance of Program}

It is a legitimate concern to modify the way that educators are currently teaching students in the science and technology fields because the United States is currently falling behind in the area of science and technology in comparison to other countries. ${ }^{5}$ Motivating undergraduates to enter and develop in Science, Technology, Engineering and Math (STEM) degree programs is essential to changing the trend in the United States. ${ }^{6,7}$ The HARP curriculum addressed these concerns by teaching the scientific method through applying experiments in the near space field through teaching strategies that are grounded in the empirical literature on problem-based instruction . These experiments were developed by students using microelectronics (GPS, wireless, videos, miniature sensors, etc.). The program was intended to train students to practically apply theory to real-life problems to better prepare them for graduate school or employment in industry, and for students to learn to solve problems and overcome obstacles by performing original experiments in real world settings. ${ }^{8,9,10}$ Workshops hosted at Taylor University trained professors to implement HARP into one of their course curriculum. The workshops were followed by guided modeling in the implementation of the program, and then a empirically based report that helped professors improve their implementation of the program during the following semesters that the course was taught.

\section{Background of Program}

For seven years, Taylor University's HARP program has been providing students with the opportunity to apply their technical science and math instruction to interesting and relevant problems. The unique experience of a high altitude balloon launch, including team-based problem solving, prototyping, construction and direct experimentation, and the "hard" deadline 
of a launch gives students a taste of real-world project experience and has helped Taylor University's students be competitive as they pursue educational and career goals.

In Taylor University's use of the HARP program into its curriculum, students were enabled to experience every part of a truly professional research project. Once a specific problem was identified, the students are required to study the theory needed to perform their desired research. This process began in the classroom, as a sense of ownership was built, students explored how best to perform their research. This resulted in theory retained and proceduralized into a skill. ${ }^{3}$

Students were required to do background research on their chosen investigation, which enables them to ideate, prototype, build and test their own instruments. Projects included such experiments as the adaptation of Geiger counters for high-altitude energetic particle sensing and the modification of an electrocardiogram to sense e-fields in the atmosphere.

Fig: A typical high-altitude flight profile

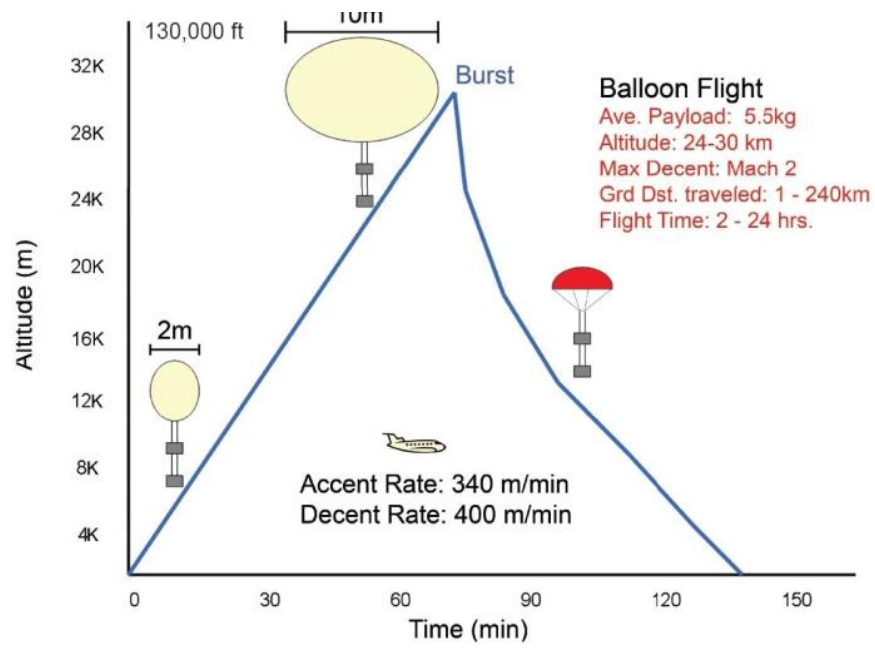

Students were able to contextualize the content and skills they were learning in highaltitude balloon experiments. There were procedures which needed to be followed to ensure a successful launch, profitable data collection, and safe recovery of their payload. Students experienced the excitement of a launch and effective post-launch operations. While working in a "mission control" environment, students kept track of their data, and kept track of the progress made by the recovery team.

For each flight, payloads were constructed modularly and connected to the primary telemetry pod via a wireless network (using the $50 \mathrm{kbaud}$ Zigbee wireless protocol). Once all of the experiment payloads had been verified and a communications link had been established between the telemetry pod, the recovery team, and the mission control center, the payload is released and ascends to altitudes ranging from 15 to 20 miles, beyond $98 \%$ of the earth's atmosphere (see fig). Throughout the flight experiment, position telemetry is reported over a 110 kbit link via $900 \mathrm{MHz}$ spread-spectrum radios, and backup position data was broadcast via Amateur Radio APRS technology. During ascent, the balloon expanded due to the reduced pressure, but eventually the balloon burst and the payload returned on a parachute with a vertical 
velocity at touchdown of approximately 1000 feet per minute, gentle enough to be safely caught by hand.

Due to technical skills and the practical educational applications of integrating this curriculum tool, professors needed to be effectively trained, given technical support as they implement the program, and feedback in how effectively they are doing at integrating it into their curriculum. The goal of the workshop was to provide training and being assured of continual support and feedback as they implemented the program into their curriculum.

Assessing Learning and Evaluating Innovations

Theory Base

A problem-based instructional model was implemented in the STEM educational experience. ${ }^{3}$ This educational model assumes that learning and doing are inseparable to the learning process. The intellectual goal of this model is to develop an undergraduate student's cognitive skills and strategies through sustained participation within a community of learning. ${ }^{11,12,13}$ In this model of learning, students are able to see how experts tackle problems, and learn to solve problems through a mentoring process. ${ }^{14}$

Research Design

A mixed factor design was used to compare pretests vs. posttests of undergraduate classes (within subjects) and four groups with different amounts of implementation (between subjects). A pre-test posttest within group design was used to measure the changes in the students' intrinsic motivation, valuing of science, application knowledge, cognitive skills, metacognitive skills, and content knowledge within each of the control and experimental groups. The differences between an event group (no problem-based curricular changes), a novice group first year implementation of problem-based HARP curriculum), an experienced group (two or three attempts of implementation with feedback) and an expert group (four or more times of problem-based implementation of HARP) were investigated.

\section{Definition of dependent variables}

Intrinsic Motivation

Students' intrinsic motivation were measured using Lepper's modified model for intrinsic motivation. The model includes contextualization, curiosity, challenge, control, and cooperation. $15-16$

1. Contextualization or application means to overtly or covertly personalize knowledge to current or future life situations in order to change and grow.

2. Curiosity is generated when new information creates inconsistencies or discrepancies in people's prior knowledge or their present expectations. Curiosity generates a feeling of wanting to investigate, become involved, or expand oneself to incorporate new information and have new experiences with the person or object that created the interest ${ }^{17}$. 
3. Challenge means calling a person to a demanding task that requires special effort and dedication in a supportive group.

4. Control is the perception that one is an origin of the activities she attempts rather than a pawn. The student will believe that he or she has self determined the activity undertaken or the product created.

5. Cooperation means to pursue win-win situations where you and the other individual grow, accomplish tasks, and enjoy the process together. In this learning structure, knowledge is gained by support, participation and nurturing with others. ${ }^{18,19}$

These areas of motivation were assessed because of their strong connection to achievement, spending time on complex activities, learning and growth goals, the use of deeper and more reflective strategies for learning, more risk taking and the focus on the learning process. $^{16}$

Valuing Science

It was a goal of the HARP program for students to learn to value science education, discovery and future careers in science. This goal were assessed by measuring the increase in students valuing the problem solving process, the calibration process, the scientific method in application to real life problems, documenting for repeatability, data analysis, metacognitive planning, monitoring and assessing, cooperation for scientific advancement, and time management for meeting deadlines.

\section{Application Knowledge}

Application knowledge is procedural content that allows a student to be able to access information successfully during a cognitive operation. Students' knowledge of how to apply problem solving, the process of prototyping, the processes of evaluation and calibration, and the ability to perform precise documentation were evaluated.

\section{Metacognitive Processes}

The metacognitive processes of control (planning and assessing) and monitoring of one's cognitive processes were assessed to see if they increase through the student's participation in the HARP program. ${ }^{20,21,22}$ Metacognitive planning involves stating a goal, selecting an operation, identifying potential obstacles or errors, identifying ways to recover from the obstacles, and predicting results desired and or anticipated. Metacognitive assessing involves evaluating goal achievement, judging accuracy and adequacy of the results, evaluating appropriateness of procedures used, assessing how well one handled the appropriateness of procedures used, assessing handling of obstacles, and judging the efficiency of the plan and its execution. Metacognitive monitoring involves keeping the goal in mind, keeping one's place in a sequence, knowing when a sub-goal has been achieved, deciding when to go on to the next operation, spotting errors or obstacles, and knowing how to recover from errors or obstacles. Metacognition has been selected to be assessed because of its key role in transferring knowledge and skills, 3,5 effective problem solving, ${ }^{3}$ thinking and learning, ${ }^{22,24,25}$ and memory. ${ }^{13,26}$ 


\section{Cognitive Skills}

A cognitive skill is a mental operation that requires the integration of knowledge into a system of procedural steps to perform a complex activity at the appropriate time. The increased ability to use the cognitive skills of problem solving (trouble shooting), prototyping, evaluation and calibration, the scientific method, documenting for repeatability, and skillful data analysis were assessed. ${ }^{5,6}$

\section{Content Knowledge}

The content students acquired were measured in the areas of primary technical knowledge, learning cycle knowledge, and operations knowledge. Primary technical knowledge relates to the vocabulary, instrumentation, and knowledge of the technical processes that pertains to the balloon launch process. Learning cycle knowledge assesses the student's knowledge of the steps in both the learning cycle and scientific method. Operations knowledge assesses the student's awareness of the rules and regulations regarding launching a high altitude balloon.

\section{Hypotheses}

Hypothesis 1 - Problem-Based Learning

The event group (control group), which did not use a problem-based teaching approach in implementing the HARP program would do significantly worse than the novice group, experienced group, and the expert group who did use a problem-based teaching approach in implementing the HARP program on key educational variables. These variables included the intrinsic motivation, valuing of science, application knowledge, metacognitive skills, cognitive skills, and content knowledge.

Hypothesis 2 - Specific Feedback Improvements

Professors that integrated a problem-based teaching approach in implementing the HARP program with guided improvement suggestions two or three times (experienced group) would be able to achieve growth in their students that equals the expert group classrooms. The educational variables that growth were assessed on were intrinsic motivation, the valuing of science, application knowledge, cognitive skills, metacognitive skills, and content knowledge.

Hypothesis 3 - Continual Expert Improvements

Expert groups that continue to be evaluated and receive constructive feedback on how to improve their problem-based teaching approach in implementing the HARP program into their curriculum would show significant improvement. Improvements were assessed on the key educational variables of intrinsic motivation, valuing science, application knowledge, cognitive skills, metacognitive skills, and content knowledge. 
Methods

As a part of the CCLI NSF grant, instruments were developed that measured the dependent variables mentioned above. Statistical procedures were conducted that supported the reliability and validity of these instruments.

Over a three-year period, 29 science classrooms that contained 849 students were compared based on whether a problem-based learning approach to teaching science using a HARP program was implemented and how many semesters a professor integrated the problem based learning approach with specific feedback on student's progress. Each of the 29 classes were given a pretest prior to any discussion of the HARP program and at the end of the class after the data from the students data analysis and presentations were completed. The classes were compared on the amount of growth that occurred in the students due to the implementation of the problem-based learning approach using the HARP program.

\section{HARP Assessment Instrument}

The HARP Assessment Instrument is a 119 item survey using a Likert Scale ranging from one to six, six being the highest. This instrument measures student development in the areas of intrinsic motivation, valuing science, application knowledge, metacognitive processes, cognitive skills, and content knowledge. Each area is broken down into several sub-scales (See Table 3).

Reliability

Reliability addresses whether an instrument will produce the same results each time it is administered to the same person in the same setting. Extensive reliability tests were conducted individually on each of the three studies. The overall pre-test Cronbach's alpha $(\alpha=.976)$ and the post-test Cronbach's alpha $(\alpha=.965)$ are both excellent. These results indicate that the HARP assessment instrument is reliable.

Validity

Validity is the extent to which a test measures what it claims to measure. Professors experienced in testing methods, professors who were instrumental in creating the HARP program, and staff familiar with HARP worked together to develop questions that would accurately assess student growth as the result from the participation in HARP. Professors and staff directly involved in the HARP Program at Taylor University performed a content evaluation to ensure construct validity. Each question was analyzed by experts to determine if it captured the type of growth a student would ideally experience from participation in the HARP program.

The known group difference method was applied in two different ways to indicate construct validity of the HARP assessment instrument in a pilot investigation. First, the significant growth from pre-test to post-test indicates the instrument captured the changes 
occurring within students. Second, it can be expected that the engineering majors will score higher on the HARP pretest assessment instrument than students in a general education astronomy class. This assumption is reasonable because the engineering students already have a greater scientific knowledge base than the other classes. They would be expected to score higher in areas assessing content knowledge, valuing science, and intrinsic motivation because they have chosen to be involved in scientific study and they have had more experience in STEM fields. If they did not score higher, then something is wrong with the instrument. Indeed, both the pre-test and post-test scores in our pilot study for the Principles of Engineering courses were much higher $(p<.05)$ than those of the Introduction to Astronomy class on three of the six categories on the pre-test and five of the six categories in the post test. These difference indicated the construct validity of our instrument.

\section{Subjects}

There were 39 participants in the Fall of 2007, 111 in the Fall of 2008, 198 in the Spring of 2009, 208 in the Fall of 2009, and 298 in the Spring of 2010. There were 446 males and 360 females with 43 students that did not indicate their gender of the 849 participants. The students had various degrees of academic science focus with 191 students coming from a hard science background, 79 students coming from a soft science background, 281 students coming from a non-science background and the rest of the students did not provide information to determine their background. There were 201 students who were freshman, 189 sophomores, 97 juniors, 97 seniors and 265 students did not provide this information.

There were 682 students who were taking the class as a general education class where the HARP program was implemented and 167 students were planning to take upper division classes in the sciences and 74 students who were currently involved in upper division science classes.

\section{Professor Demographics}

There were professors teaching the problem-based learning approach using HARP from 12 different states in the U.S.A., 18 different universities, with various teaching experience with a bimodal distribution of 6-10 (six professors), and 21 or more years (four professors). All the professors attended a workshop that was sponsored by the professors in the expert group to prepare them for implementing the program.

\section{Experimental Groups}

The event group (control) consisted of 15 students, the novice group had 354 students, the experienced group had 190 students, and the expert group had 290 students.

\section{Group 1: Event Group (Control group)}

Schools that did not integrate the HARP program into their curriculum and did the launch as a week event under the supervision of Taylor University (1 Class; 15 students) 
Group 2: Novice Group

Schools that have done their first Balloon launch under the guidance of Taylor University during a semester within the curriculum of their classes (15 Classes; 354 Students).

Group 3: Experienced Group

Schools that have done either their $2^{\text {nd }}$ or $3^{\text {rd }}$ launch under the guidance of Taylor University during a semester with feedback for improvement within the curriculum of their classes (8 Classes, 190 Students).

\section{Group 4: Expert Group}

Schools that have done more than three launches under the guidance of Taylor University during a semester with feedback for improvement within the curriculum of their classes (5 Classes; 290 Students).

Results

Hypothesis

Hypothesis 1 - Problem-Based Learning

Graph 1

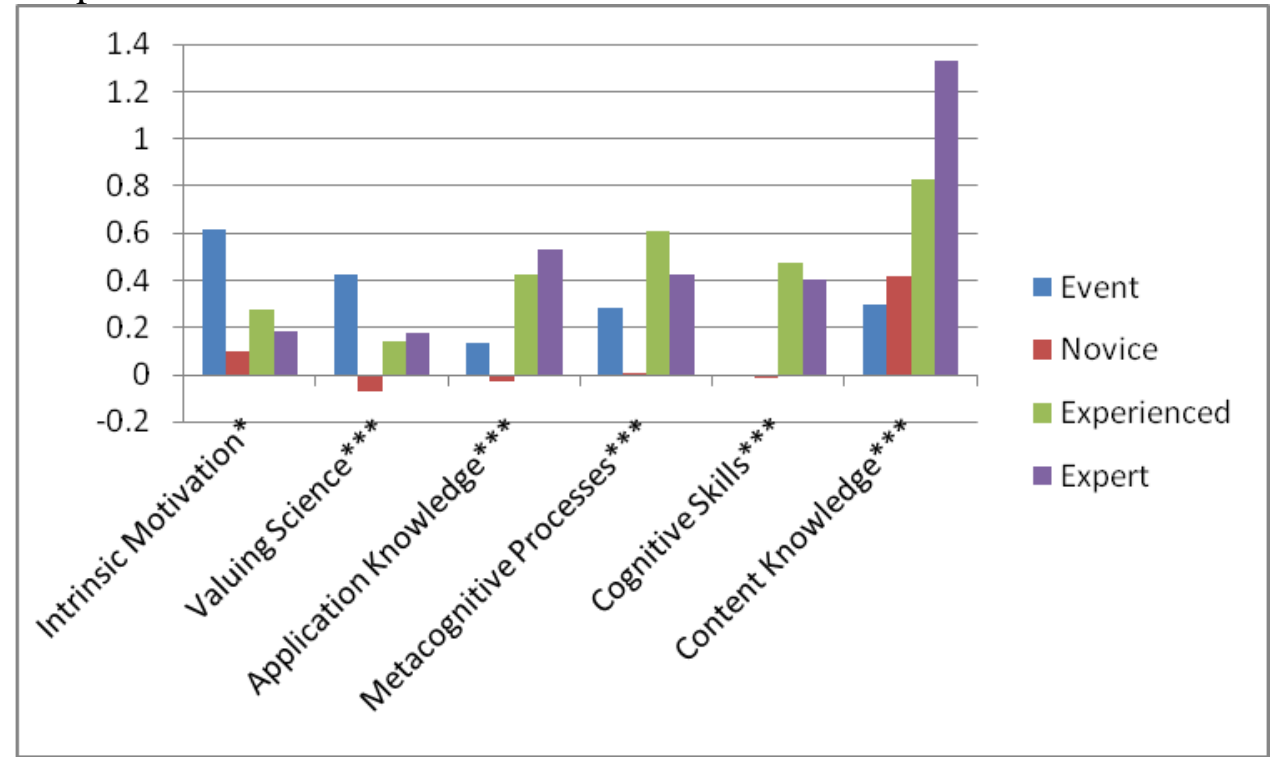

The event group (control group) who did not use a problem-based teaching approach in implementing the HARP program did significantly worse than the novice group, experienced group, and the expert group who did use a problem-based teaching approach in implementing the HARP program. These differences occurred in the students' intrinsic motivation, valuing of science, application knowledge, cognitive skills, metacognitive skills, and content knowledge. 
When comparing the event group (control group), novice group, experienced group, and the expert group, there was a statistically significant difference between them in intrinsic motivation $(\mathrm{p}<.05)$, valuing science $(\mathrm{p}<.001)$, application knowledge $(\mathrm{p}<.001)$, metacognitive processes $(\mathrm{p}<.001)$, cognitive skills $(\mathrm{p}<.001)$, and content knowledge $(\mathrm{p}<.001)$. The statistical differences between the groups indicated that there needed to be a direct implementation - not just a one-time event - of the HARP program within the curriculum, repetition of the implementation at least two times, and guided improvements in instructional methods. See graph 1 .

Hypothesis 2 - Specific Feedback Improvements

Professors that integrated a problem-based teaching approach in implementing the HARP program with guided improvement suggestions two or three times (experienced group) were able to achieve growth in their students that equals the expert group classrooms. Students showed significant growth on intrinsic motivation, valuing of science, application knowledge, cognitive skills, metacognitive skills, and content knowledge.

Professors that integrated the HARP curriculum into their classes with guided improvement suggestions two or three times (experienced group) were able to achieve growth in their students in key educational variables equivalent to that observed in the expert group classrooms. The experienced group showed significant statistical changes from the students pretest to posttest in intrinsic motivation $(\mathrm{p}<.001)$, valuing science $(\mathrm{p}<.01)$, application knowledge $(\mathrm{p}<.001)$, metacognitive processes $(\mathrm{p}<.001)$, cognitive skills $(\mathrm{p}<.001)$, and content knowledge $(\mathrm{p}<.001)$. The experienced group's educational gains were found to be practically significant in the key educational objectives of metacognitive processes $\left(\eta^{2}=.221\right)$, and content knowledge $\left(\eta^{2}=.387\right)$. See table 1 .

Table 1. Experimental Groups Compared on Educational Variables

Table 1. Significance Levels

$*: \mathrm{p}<.05$
$* *: \mathrm{p}<.01$
$* * *: \mathrm{p}<.001$
No $*: \mathrm{p}>.05$

\begin{tabular}{|c|c|c|c|}
\hline 1: EVENT GROUP & 2: NOVICE GROUP & $\begin{array}{l}\text { 3: EXPERIENCED } \\
\text { GROUP }\end{array}$ & 4: EXPERT GROUP \\
\hline $\begin{array}{l}\text { 1. Intrinsic Motivation } \\
\text { a. } \\
\text { Contextualization* } \\
\text { b. Curiosity* } \\
\text { c. Challenge** } \\
\text { d. Control } \\
\text { e. Cooperation }\end{array}$ & $\begin{array}{l}\text { 1. Intrinsic } \\
\text { Motivation* } \\
\text { a. } \\
\text { Contextualization } \\
\text { b. Curiosity } \\
\text { c. Challenge** } \\
\text { d. Control } * * * \\
\text { e. Cooperation*** }\end{array}$ & $\begin{array}{l}\text { 1. Intrinsic } \\
\text { Motivation*** } \\
\text { a. } \\
\text { Contextualization** } \\
\text { b. Curiosity*** } \\
\text { c. Challenge } \\
\text { d. Control** } \\
\text { e. Cooperation*** }\end{array}$ & $\begin{array}{l}\text { 1. Intrinsic } \\
\text { Motivation*** } \\
\text { a. } \\
\text { Contextualization } \\
\text { b. Curiosity*** } \\
\text { c. Challenge } \\
\text { d. Control*** } \\
\text { e. Cooperation*** }\end{array}$ \\
\hline 2. Valuing $S$ & 2. Valuing Science & 2. Valuing Science* & $\begin{array}{l}\text { 2. Valuing } \\
\text { Science*** }\end{array}$ \\
\hline
\end{tabular}




\begin{tabular}{|c|c|c|c|}
\hline $\begin{array}{l}\text { 3. Application } \\
\text { Knowledge } \\
\text { a. Apply Problem } \\
\text { Solving } \\
\text { b. Process of } \\
\text { Prototyping } \\
\text { c. Process of } \\
\text { Evaluation } \\
\text { d. Documentation } \\
\text { and Reports }\end{array}$ & $\begin{array}{l}\text { 3. Application } \\
\text { Knowledge } \\
\text { a. Apply Problem } \\
\text { Solving* (decrease) } \\
\text { b. Process of } \\
\text { Prototyping } \\
\text { c. Process of } \\
\text { Evaluation } \\
\text { d. Documentation } \\
\text { and Reports }\end{array}$ & $\begin{array}{l}\text { 3. Application } \\
\text { Knowledge*** } \\
\text { a. Apply Problem } \\
\text { Solving*** } \\
\text { b. Process of } \\
\text { Prototyping *** } \\
\text { c. Process of } \\
\text { Evaluation*** } \\
\text { d. Documentation } \\
\text { and Reports }\end{array}$ & $\begin{array}{l}\text { 3. Application } \\
\text { Knowledge*** } \\
\text { a. Apply Problem } \\
\text { Solving * } \\
\text { b. Process of } \\
\text { Prototyping*** } \\
\text { c. Process of } \\
\text { Evaluation*** } \\
\text { d. Documentation } \\
\text { and Reports*** }\end{array}$ \\
\hline $\begin{array}{l}\text { 4. Metacognitive } \\
\text { Processes } \\
\text { a. Metacognitive } \\
\text { Planning } \\
\text { b. Metacognitive } \\
\text { Assessing } \\
\text { c. Metacognitive } \\
\text { Monitoring }\end{array}$ & $\begin{array}{l}\text { 4. Metacognitive } \\
\text { Processes } \\
\text { a. Metacognitive } \\
\text { Planning*** } \\
\text { b. Metacognitive } \\
\text { Assessing } \\
\text { c. Metacognitive } \\
\text { Monitoring }\end{array}$ & $\begin{array}{l}\text { 4. Metacognitive } \\
\text { Processes*** } \\
\text { a. Metacognitive } \\
\text { Planning*** } \\
\text { b. Metacognitive } \\
\text { Assessing*** } \\
\text { c. Metacognitive } \\
\text { Monitoring*** }\end{array}$ & $\begin{array}{l}4 \text { Metacognitive } \\
\text { Processes*** } \\
\text { a. Metacognitive } \\
\text { Planning*** } \\
\text { b. Metacognitive } \\
\text { Assessing*** } \\
\text { c. Metacognitive } \\
\text { Monitoring*** }\end{array}$ \\
\hline 5. Cognitive Skills & 5. Cognitive Skills & 5. Cognitive Skills*** & 5. Cognitive Skills*** \\
\hline $\begin{array}{l}\text { 6. Content Knowledge } \\
\text { a. Primary } \\
\text { Technical Knowledge } \\
\text { b. Learning Cycle } \\
\text { Knowledge } \\
\text { c. Operations } \\
\text { Knowledge ** }\end{array}$ & $\begin{array}{l}\text { 6. Content } \\
\text { Knowledge*** } \\
\quad \text { a. Primary } \\
\text { Technical } \\
\text { Knowledge*** } \\
\text { b. Learning Cycle } \\
\text { Knowledge*** } \\
\text { c. Operations } \\
\text { Knowledge*** }\end{array}$ & $\begin{array}{l}\text { 6. Content } \\
\text { Knowledge*** } \\
\text { a. Primary } \\
\text { Technical } * * * \\
\text { Knowledge*** } \\
\text { b. Learning Cycle } \\
\text { Knowledge*** } \\
\text { c. Operations } \\
\text { Knowledge*** }\end{array}$ & $\begin{array}{l}\text { 6. Content } \\
\text { Knowledge*** } \\
\quad \text { a. Primary } \\
\text { Technical } \\
\text { Knowledge*** } \\
\text { b. Learning Cycle } \\
\text { Knowledge*** } \\
\text { c. Operations } \\
\text { Knowledge*** }\end{array}$ \\
\hline
\end{tabular}


Hypothesis 3 - Continual Expert Improvements

Graph 2

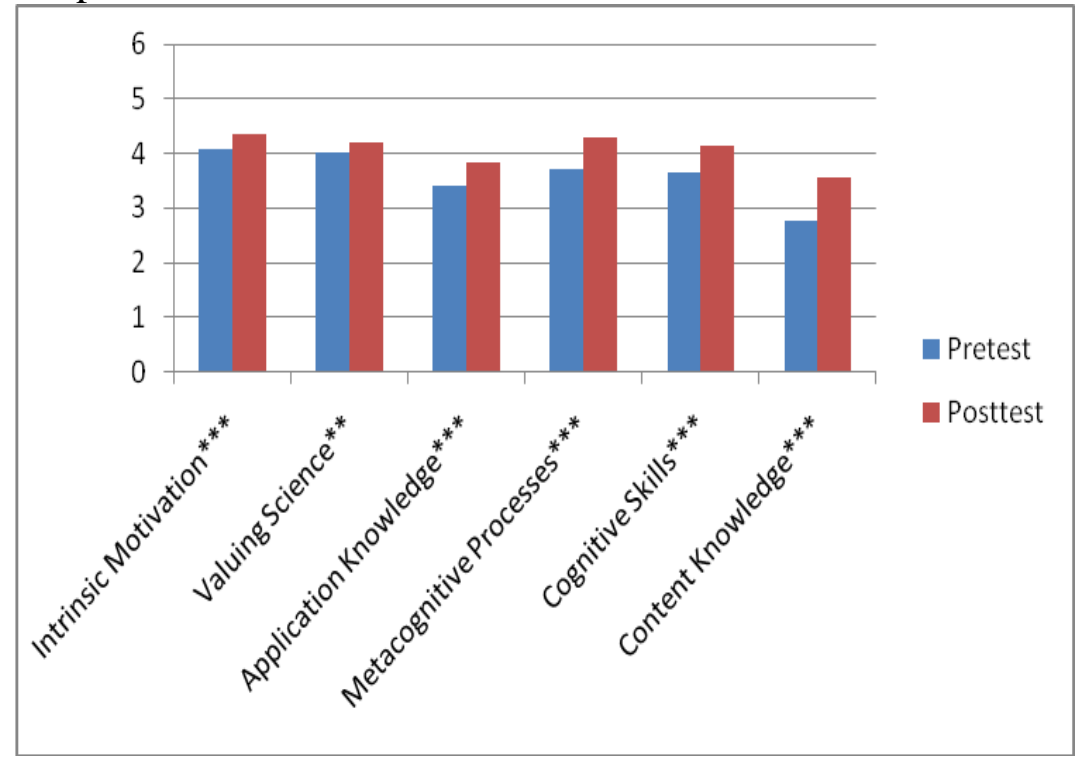

Table 1. Statistical

Significance Levels

$\mathrm{p}<.05-*$

$\mathrm{p}<.01-* *$

$\mathrm{p}<.001-* * *$

$p>.05$

Graph 3

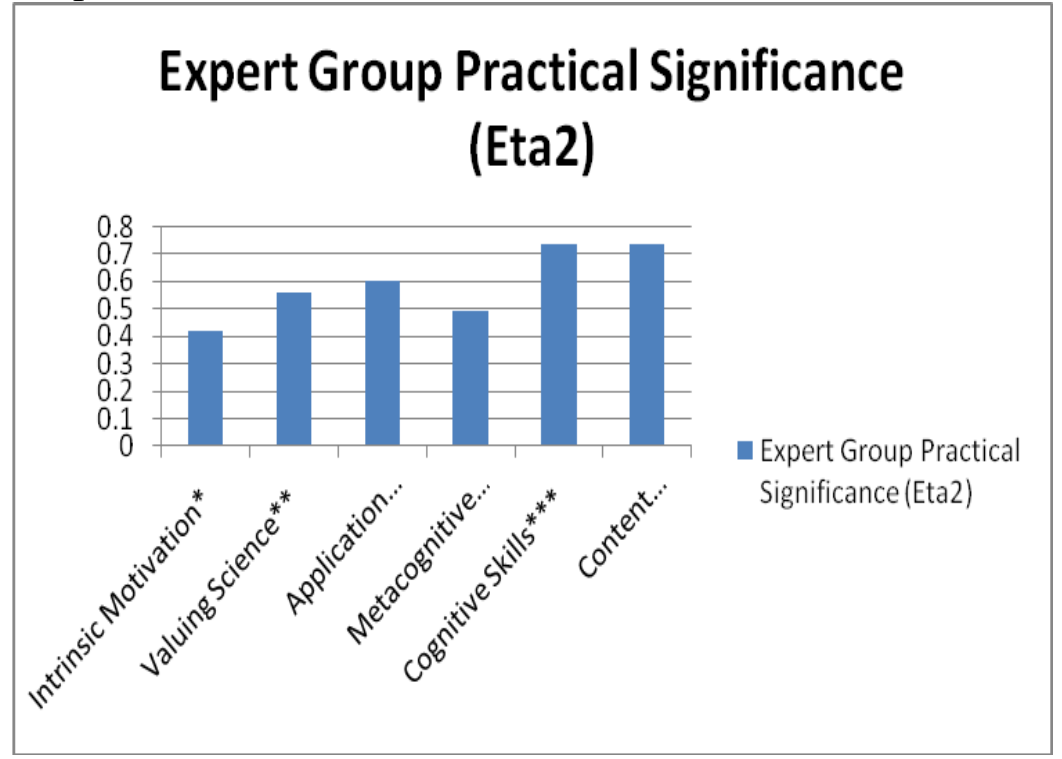

Practical Significance

Levels

* Low Practical

Significance

** Medium Practical

Significance

*** High Practical

Significance

Expert groups that continue to be evaluated and receive constructive feedback on how to improve their problem-based teaching approach in implementing the HARP program into their curriculum showed significant improvement on intrinsic motivation, valuing of science, application knowledge, cognitive skills, metacognitive skills, and content knowledge.

The expert groups continued to be evaluated and received constructive feedback on how to improve their problem-based teaching approach in implementing the HARP program into their 
curriculum. After four semesters of implementation and feedback on how to improve, all major educational variables measured were both statistically and practically significant when comparing their students' improvements from pretests to posttests. The statistical and practical significance of the students' improvement during the semester occurred in intrinsic motivation $\left(\mathrm{p}<.001 ; \eta^{2}=.418\right)$, valuing science $\left(\mathrm{p}<.001 ; \eta^{2}=.559\right)$, application knowledge $\left(\mathrm{p}<.001 ; \eta^{2}=\right.$ $.602)$, metacognitive knowledge $\left(p<.001 ; \eta^{2}=.492\right)$, cognitive skills $\left(p<.001 ; \eta^{2}=.738\right)$, and content knowledge $\left(p<.001 ; \eta^{2}=.738\right)$. See graphs 1 and 2 .

When comparing the first and the last semester net gain scores that the expert group implemented the problem-based learning approach using HARP, the last semester was statistically significantly higher in intrinsic motivation $(\mathrm{p}<.01)$, valuing science $(\mathrm{p}<.001)$, application knowledge $(\mathrm{p}<.001)$, metacognitive processes $(\mathrm{p}<.001)$, cognitive skills $(\mathrm{p}<.01)$, and content knowledge $(\mathrm{p}<.001)$.

Demographic Variables

Gender Comparisons

Graph 4

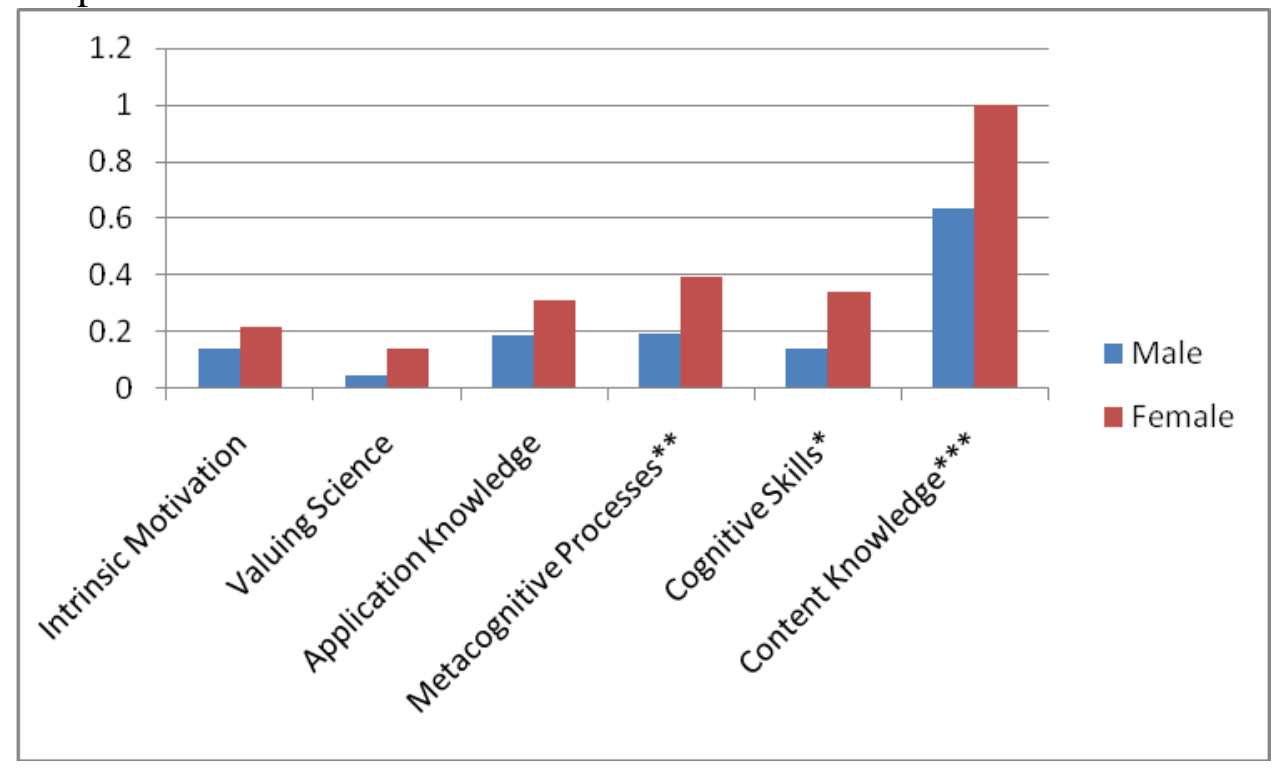

The HARP program had a greater impact on females than males in the general categories of Metacognition ( $p<.01)$, Cognitive Skills $(\mathrm{p}<.05)$, and Content Knowledge $(\mathrm{p}<.001)$. Within the categories of intrinsic motivation, females perceived they gained more in curiosity $(\mathrm{p}<.05)$ in learning than males. In the area of Application Knowledge, the subscale area of evaluation ( $\mathrm{p}<.001)$ showed significantly higher improvement for females than males. Under Metacognitive Processes, females gained more than males in the subcategories of planning $(\mathrm{p}<.01)$, and assessing $(\mathrm{p}<.01)$. In the general category of Content Knowledge, females gained more than males in the subcategories of primary technical knowledge, and learning cycle knowledge. This is important due to the lack of females that are currently involved in the sciences. 
Academic Major

Graph 5

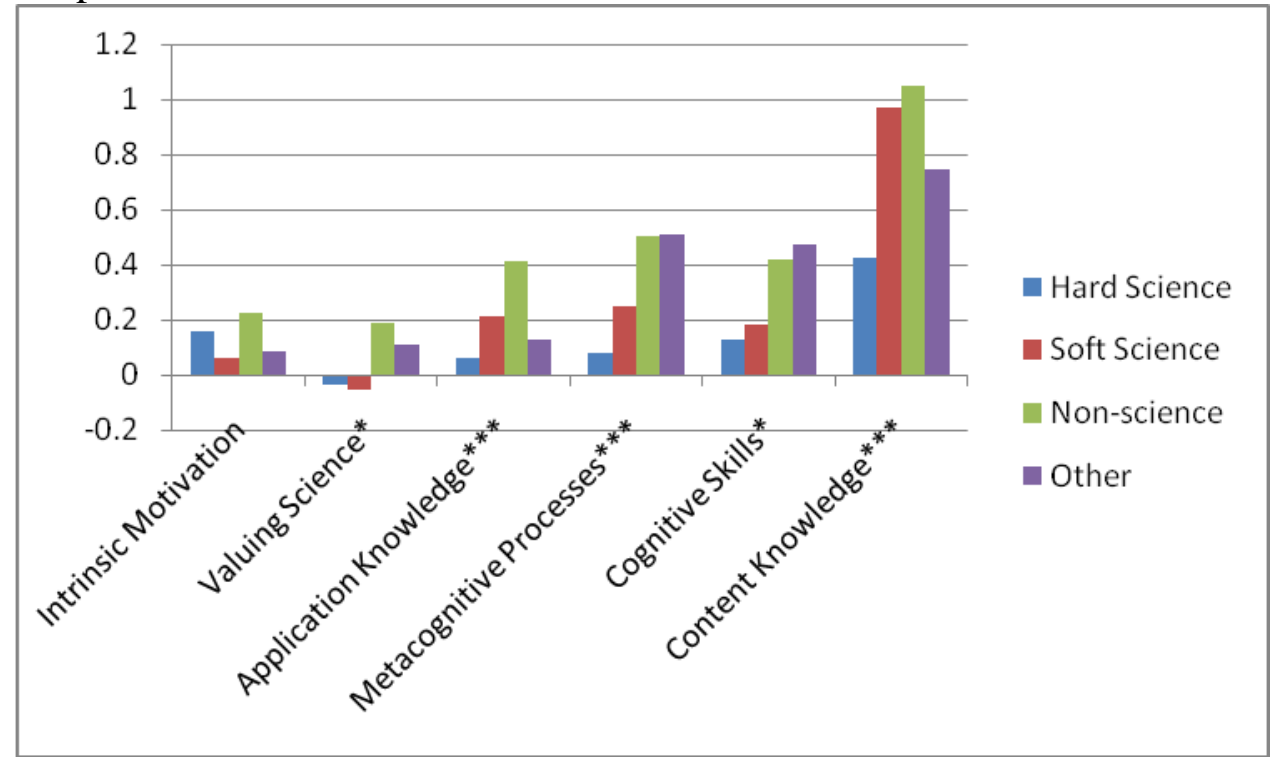

Non-science majors gained more from the HARP experience than science oriented majors in the general areas of Valuing Science $(\mathrm{p}<.05)$, Application Knowledge $(\mathrm{p}<.001)$, Cognitive Skills $(\mathrm{p}<.05)$, Metacognitive Knowledge ( $<<.001)$, Cognitive Skills $(\mathrm{p}<.05)$, and Content Knowledge $(\mathrm{p}<.001)$. In the subscale of intrinsic motivation, the non-science participants gained significantly more than hard and soft science majors in the area of curiosity in science $(\mathrm{p}<.01)$. In the general category of Application Knowledge, non-science majors gained more than any other major in problem solving $(\mathrm{p}<.05)$, prototyping $(\mathrm{p}<.05)$, evaluation $(\mathrm{p}<.01)$, and documentation $(\mathrm{p}<.01)$. In the general category of Metacognitive Processes, non-science majors gained more than the hard and soft science majors in the subcategories of planning $(\mathrm{p}<.001)$, monitoring $(\mathrm{p}<.01)$, and assessing $(\mathrm{p}<.01)$ In the general area of Content Knowledge, non-science majors gained more from participating in the HARP experience than soft science majors in the areas of primary technical knowledge $(\mathrm{p}<.001)$, and learning cycle knowledge $(\mathrm{p}<.001)$.

Students taking lower level classes gained more than students in upper level classes in the areas of Valuing Science ( $\mathrm{p}<.01)$, Application Knowledge $(\mathrm{p}<.001)$, Metacognitive Processes $(\mathrm{p}<.001)$, Cognitive Skills $(\mathrm{p}<.01)$, and Content Knowledge $(\mathrm{p}<.001)$. In a reversal of these general findings, the upper division classes that implemented HARP in their classes gained more in the area of the intrinsic motivation area of control $(\mathrm{p}<.05)$. In the general area of Application Knowledge, the students in general education classes gained more from the HARP experience than upper division classes in the areas of prototyping ( $p>001)$, evaluation $(p<.001)$, and documentation $(\mathrm{p}<.05)$. In the general category of Metacognitive Processes, general education classes gained more in the areas of planning $(\mathrm{p}<.01)$, monitoring $(\mathrm{p}<.05)$, and assessing $(\mathrm{p}<.001)$ when compared to students who were science majors in the lower division classes. The nonscience (general education) students who were not science majors gained significantly more from the HARP experience than students in other majors in the general area of Content Knowledge 
and in its subcategories of primary technical knowledge $(\mathrm{p}<.001)$, and learning cycle knowledge $(\mathrm{p}<.001)$.

\section{Conclusion}

\section{Hypothesis 1 - Problem-Based Learning}

The event group (control group), which did not use a problem-based teaching approach when implementing the HARP program did significantly worse than the novice group, experienced group, and the expert group who did use a problem-based teaching approach in implementing the HARP program on valuing of science, application knowledge, cognitive skills, metacognitive skills, and content knowledge. It appears that a problem-based approach without intentional instructional interventions (event group) had very little impact on student's perceptional growth on key educational variables except the intrinsic motivational variables.

Intrinsic motivation, such as curiosity, contextualization, and challenge did exhibit significant growths. The growth in curiosity may be due to the excitement of being able to do a see novel footage of a balloon launch and then get to experience it within a day. The other groups had the opportunity to experience these two aspects but they were distributed over a semester so the intensity of the elements that stimulated curiosity were dulled. The shortened time frame, and the educators' unfamiliarity with the materials, may have increased the challenge of the project for the students.

Such increases were considerably more in the Novice group. This group, made up of first-time participants of the problem-based HARP curriculum, saw considerable increases in the areas of content knowledge. This would be a logical finding; in order to perform higher cognitive functions, one must first know the basic facts. In addition, this group saw a significant increase in metacognitive planning, the ability to lay out a plan before beginning a project, and intrinsic motivation, including subscales challenge, cooperation, and control. While challenge may have still been influenced by the educators' lack of experience with the equipment, cooperation and control, which continued to show significant increases as the educators gained experience, are essential parts to project-based learning.

\section{Hypothesis 2 - Specific Feedback Improvements}

The Experienced group, which contained groups who were doing their second or third launches with specific evaluations and suggestions for instructional improvement, and the Expert group, which consisted of experts who had performed four or more launches - as they implemented the project in their own classrooms, saw almost identical increases. Students in both groups exhibited significant increases in all main scales and all but two subscales in both groups. Challenge and Documentation did not increase in the Experienced group and Contextualization and Challenge did not change in the Expert group. This means that the suggestions for instructional improvement made by Taylor University evaluators have successfully aided educators in improving their educational techniques to achieve levels of growth similar to those seen at Taylor University. 
Hypothesis 3 - Continual Expert Improvements

The expert groups continued to be evaluated and received constructive feedback on how to improve their problem-based teaching approach in implementing the HARP program into their curriculum. After four semesters of implementation and feedback on how to improve, all major educational variables measured were both statistically and practically significant when comparing their students' improvements from pretests to posttests.

The quality of problem-based learning in science classes seem to be proportional to the number of times instructors goes through the process of evaluating their classes on key instructional variables and seek to implement specific educational suggestions. There did not seem to be a leveling off of the growth in students in each major education variable. This data suggests that problem-based classes should go through a continuous improvement cycle to reap maximum practical significance change in students. It also suggests that when problem-based learning is assessed that researchers should not only look at the specific design of the class but how many times the class has gone through a cycle of implementation, evaluation, and improvements made. The comparison of newly developed problem-based learning classes with traditional classroom instruction that has occurred the same way seems to have missed a key variable in why students improve on key educational variables.

Demographic Variables

Gender

The larger perceived gains of females compared to males in metacognitive processes, curiosity, evaluative application knowledge, cognitive skills, and content knowledge due to this problem-based HARP curriculum is important for attracting and developing females in the STEM fields. A problem-based teaching approach in teaching STEM classes might be very instrumental for women believing in the practical and exciting activities that they can participate in if they enter the STEM fields. To attract women to the STEM fields, they need to take STEM classes early in their academic life that stress problem-based curriculum in contrast to the traditional introductory classes that stress information to be memorized without direct application.

Academic Major

Non-science majors had the largest perceived gains in key educational variables due to the problem-based HARP curriculum. It is possible that non-science majors understand the process and benefits when they participate in doing science than just be lectured about what science is. Educators in the STEM fields need to help students to see the value of STEM fields by getting the students involved in the process of conducting experiments that they can carry through using the whole scientific method. The general education classes that all students need to take in the sciences need to provide a problem-based component to attract students to the STEM fields or develop cognitive skills, application knowledge, content knowledge, metacognitive skills, and value science as a way of thinking scientifically. 


\section{Reference List}

1. Segers, Dochy, F., \& Cascallar, E, (2003). Optimizing new modes of assessment: In search of qualities and standards. Boston/Dordrecht: Kluwer Academics.

2. Shui-fong, L., Wing-yi, C., \& William, Ma. (2009). Teacher and student intrinsic motivation in project-based learning. Instructional science: An international journal of the learning of the learning sciences, 37(6).

3. Gijbels, D., Dochy, F., Bossche, P.V. (2005). Effects of Problem-Based Learning: A meta-analysis from the angle of assessment. Review of Educational, 75 (1) 27-61.

4. Nandi, P., Clan, J., Chan, C., Ghan, P., \&Chan, L (2000). Undergraduate medical education: Comparison of problem-based learning and conventional teaching. Hong Kong Medical Journal, 6(3).

5. Koehn, E. (2004) Enhancing civil engineering education and ABET criteria through practical experience. Journal of Professional Issues in Engineering Education \& Practice, 130, 77-83.

6. Karukstis, K. (2007). Facilitating advanced study in science and engineering: The CUR Registry of Undergraduate Researchers. Journal of Chemical Education, 84, 1744-1745.

7. Henry, C. (2005). REU Directors put heads together. Chemical \& Engineering News, 83(43), 99. Retrieved from Academic Search Premier database.

8. Hartmann, D. (1990). Undergraduate research experience as preparation for graduate school. American Sociologist, 21, 179-188.

9. Sabatini, D. A. (1997) Teaching and research synergism: The undergraduate research experience. Journal of Professional Issues in Engineering Education \& Practice, 123, 98-101.

10. Susan H., R., Hancock, M., \& McCullough, J. (2007). Benefits of undergraduate research experiences. Science, 316(5824), 548-549. doi:10.1126/science.1140384.

11. Brown, J. S., Collins, A., \& Duguid, (1989). Situated cognition and the culture of learning. Educational Researcher, 18, 32-42.

12. Collins, A, Brown, J. S., \& Newman, (1989). Cognitive apprenticeship: Teaching students the craft of reading, writing, and mathematics. In L. Resnick (Ed), Knowing, learning, writing, and instruction: Essays in honor of Robert Glaser (pp. 453-493). Hillsdale, NJ: Erlbaum.

13. Jarman, R. F., Vavrik, J., \& Walton, P. D. (1995). Metacognition and the frontal lobe processes: At the interface of cognitive psychology and neropsychology. Genetic, Social, and General Psychology Monographs, 121, 153-210.

14. Palincsar, A. S., \& Brown, A. L., (1984). Reciprocal teaching of comprehension-fostering monitoring activities. Cognition \& Instruction, 1, 117-175.

15. Brown, A.L., Bransford, J.D., Ferrara, R.A., \& Campione, J.C. (1983). Learning, remembering, and understanding. In J.H. Flavell \& E.M. Markman (Eds.), Carmichael's manual of child psychology (Vol 1, pp.77-166). New York: Wiley.

16. Carlson, E.R. (1997). Experienced cognition. Mahwah, NJ: Erlbaum. 
17. Lepper, M.R. \& Henderlong, J. (2000). Turning "play" into "work" and "work" into "play": 25 years of research on intrinsic versus extrinsic motivation. In C. Sansone, J.M. Harackiewicz (Eds.), The search for optimal motivation and performance. (pp. 257-307) San Diego, CA: Academic Press.

18. Johnson, D., Johnson, R., \& Smith, K. (1991). Cooperative learning: Increasing college faculty instructional productivity (ASHE-ERIC Higher Education Report No. 4). Washington, DC: The George Washington University.

19. Johnson, R.T. (1976). The relationship between cooperation and inquiry in science classrooms. Journal of Research in Science Teaching, 31(1), 55-63.

20. Beyer, B. (1987). Practicing strategies for the teaching of critical thinking. Boston: Allyn and Bacon.

21. Flavell, J.H. (1979). Metacognition and cognitive monitoring: A new area of cognitive developmental inquiry. American Psychologist, 38, 906-911.

22. Nelson, T. O. (1996). Consciousness and metacognition. American Psychologist, 51, 102-116.

23. Belmont, J.M., Ferretti, R.P., \& Mitchell, D.W. (1982). Memorizing: A test of untrained mildly mentally retarded children's problem-solving. American Journal of Mental Deficiency, 87(2), 197210.

24. Cohen, M.S., Freeman, J.T., \& Wolf, S. (1996). Metacognition in time-stressed decision making: Recognizing, critiquing, and correcting. Human Factors, 38(2), 206-219.

25. Swanson, H. L. (1990). What developes in working memory? A life span perspective. Developmental Psychology, 35, 986-1000.

26. Moses, L., \& Barrd, J. A. (1999). Metacognition. In R. A. Wilson \& F. C. Keil (Eds.), The MIT encyclopedia of the cognitive sciences (pp. 533-534). Cambridge, MA:MIT Press. 